\title{
FORECASTING THE WAVE-CURRENT INTERACTIONS AT THE MOUTH OF THE COLUMBIA RIVER, OR, USA
}

\author{
Sarah Kassem¹, H. Tuba Özkan-Haller ${ }^{2}$
}

\begin{abstract}
An operational wave forecast of the area near the mouth of the Columbia River is presented. This region is known for its large waves and strong tidal currents. The forecast is forced with full directional spectra obtained from a refined WaveWatchIII forecast of the Pacific Northwest, and tidal current inputs are obtained from an estuarine circulation forecast of the Columbia River. The forecast has been operational since August 2011 providing short-term predictive wave information at the mouth of the Columbia River. Results from a 6-month period are promising, with a normalized root-mean-squared error (NRMSE) of $16 \%$ at the location of an inshore buoy, which is located outside the zone of tidal influence in $25 \mathrm{~m}$ water depth. Near the river mouth and in the channel, wave heights are heavily dominated by the tidal currents which significantly increase wave heights on ebb tides. Hindcast results shows that the model is able to predict the general effect of the tidal currents with a NRMSE of $30 \%$ in wave heights at the river mouth. Despite some of the model limitations, it still provides valuable information to navigators and bar pilots since it includes the effects of the tidal currents.
\end{abstract}

Keywords: Wave-current interaction; Columbia River; Forecasting; SWAN

\section{INTRODUCTION}

As the second largest river in the U.S., the Columbia River is the gateway to several commercial ports and hosts 12,000 commercial vessels and 100,000 recreational and charter vessels every year (Moritz et al. 2007). The mouth of the Columbia River (MCR) is known for its extreme wave conditions and navigation hazards. Navigation into the MCR requires skill and detailed knowledge of the area and is aided by the Columbia River Bar Pilots. These pilots, who are responsible for the safe passage of commercial vessels through the entrance, require short-term predictions of wave conditions to adequately do their job. The MCR is subject to strong tidal currents which are caused by the constriction of tidal flows through the narrow river entrance. Previous studies have shown that near the entrance, the local wave height is strongly dependent on these tidal currents. On ebb tide, these currents have the potential to increase the wave energy by $50 \%$ (González 1984; Elias et al. 2012).

In the presence of an opposing current, the wavelength will shorten which will cause the group velocity to decrease. To maintain conservation of energy flux, the wave energy will increase, resulting in an increase of wave height. In addition, opposing currents will refract the waves such that they are focused upon the area of strongest flow which will cause a further increase in wave heights. In a following current, the opposite occurs, where the wavelength increases, the group velocity increases and the wave heights are reduced.

This paper will present an experimental forecasting system for the MCR which includes the effects of wave-current interactions. Validation of the forecast occurs through a buoy located in $25 \mathrm{~m}$ water depth. To validate the model near the entrance of the river, in the area of tidal influence, a hindcast is conducted which coincides with a 4-week field experiment at the Columbia River entrance.

\section{THE MCR ENVIRONMENT}

The Columbia River is flanked by 2 large jetties which were constructed in the early 1900s to stabilize the river entrance. These jetties were built upon the naturally occurring tidal shoals, known as Peacock Spit (north shoal) and Clatsop Spit (south shoal). In front of the river entrance is the Columbia River "bar", a large fan-shaped deposit of sediment located $4 \mathrm{~km}$ west of the jetties. The river entrance requires annual dredging to maintain the navigational channel, with approximately 4.5 million cubic yards of sediment removed every year. A large portion of this dredged material is placed in specific disposal sites within the entrance of the river, adding another degree of complexity to the bathymetry (Moritz et al. 2007).

The MCR is subject to the severe wave climate of the U.S. Pacific Northwest (PNW). In the winter, storms tend to arrive from the southwest, with average wave heights of $3 \mathrm{~m}$ and periods of 12 to $13 \mathrm{~s}$, however winter storms can commonly create waves $6 \mathrm{~m}$ or more and extreme heights of 14-15 m

\footnotetext{
${ }^{1}$ School of Civil and Construction Engineering, Oregon State University, 104 CEOAS Admin BIdg., Corvallis, OR, 97331, USA. skassem@coas.oregonstate.edu

${ }^{2}$ College of Earth, Ocean, and Atmospheric Sciences, Oregon State University, 104 CEOAS Admin Bldg., Corvallis, OR, 97331, USA
} 
have occurred (Allan and Komar 2002). The summer brings milder wave conditions; the average wave height during these months is $1.2 \mathrm{~m}$ with an average period of $8 \mathrm{~s}$. Tides in the MCR are semi-diurnal with a range of 2 to $4 \mathrm{~m}$, and tidal velocities in the entrance have been known to exceed $2 \mathrm{~m} / \mathrm{s}$ on ebb tide (González 1984; Ruggiero et al. 2005). At the river entrance, the waves will focus on the tidal shoals and river bar, causing large gradients in wave heights. In addition to this, the phase of the tide can significantly increase (on ebb tides) or moderately decrease (on flood tides) the wave heights (González 1984).

Two long term data sources are available in this region. Offshore of the MCR is National Data Buoy Center (NDBC) buoy 46029, located in $134 \mathrm{~m}$ water depth, slightly shoreward of the continental shelf. Closer to the entrance is the Coastal Data Information Program (CDIP) buoy, located in $25 \mathrm{~m}$ water depth, $5 \mathrm{~km}$ southwest off the tip of the southern jetty (see Fig. 1b). At this location, the CDIP buoy is on the border of the zone of tidal influence and experiences very little change in wave heights due to tidal currents. Within the tidal zone, data acquisition becomes difficult due to the variable and extreme wave and tidal current conditions. An arbitrary output location is chosen near the entrance of the river referred to as the river mouth location (RML). Even though there is no validation at this location, it serves to highlight tidal influences.

\section{THE FORECASTING SYSTEM}

In order to forecast wave conditions at the MCR, both forecasted wave and tidal current information is required. Wave information is obtained from NearWaveWatchIII, a WaveWatchIII forecast specifically designed for the U.S. Pacific Northwest (García-Medina et al. 2012). With a finer resolution than the standard WaveWatchIII forecast, NearWaveWatchIII (NearWW3) is able to resolve the large bathymetric gradients that are typical to the coast of the PNW. This forecast covers the region of central Washington to northern California. Full directional spectra information is extracted from the forecast in hourly increments at the boundaries of the Columbia River forecast domain.

Tidal current information is obtained from SELFE, a circulation model specifically designed for the Columbia River (Zhang et al. 2004). It is a 3D baroclinic circulation model which solves the shallow water equations using the Boussinesq approximations, mass conservation and conservations of salt and heat. The main model inputs are the discharge from the Columbia River and 4 diurnal and semi-diurnal tidal components. In addition, SELFE accounts for atmospheric pressure, air temperature and specific humidity. The depth-averaged velocity field and water surface elevations obtained from the SELFE forecast are provided by the Center of Coastal Margin Observation and Prediction (CMOP).

The domain of the Columbia River forecast is $63 \mathrm{~km}$ in the longshore and $47 \mathrm{~km}$ in the cross-shore, with a resolution of $100 \mathrm{~m}$ in the longshore and $75 \mathrm{~m}$ in the cross-shore (see Fig. 1a). It is composed of 2003 Digital Elevation Model bathymetry of the Astoria domain freely available from the National Geophysical Data Center. Stitched into this dataset is a 2005 survey of the region $15 \mathrm{~km}$ north-south by $10 \mathrm{~km}$ east-west centered about the jetties, provided by the United States Army Corps of Engineers (USACE). All of the data was interpolated onto a $30 \mathrm{~m}$ x $30 \mathrm{~m}$ regularly spaced grid.

The Columbia River forecast is completed using the SWAN (Simulating WAves Nearshore) model (Booij et al. 1999). SWAN, a $3^{\text {rd }}$ generation spectral wave model, solves the action balance equation, accounting for changes due to refraction, shoaling and dissipation. Options for non-linear and wavewave interactions are available, however they are not accounted for in the forecast. Dissipation of energy occurs through breaking using the Battjes and Janssen (1978) breaking model and whitecapping using the Komen et al. (1984) dissipation scheme. Bottom friction and wind growth are not included due to the relatively small domain. The forecast starts at 01:00 daily and takes 4 hours to complete, giving 68-hours of forecasted wave information on an hourly basis. However, due to the timing of the NearWW3 and SELFE forecasts, the Columbia River forecast is delayed by 23 hours, therefore giving only 45-hours of true forecasted data.

To further investigate the results of the forecast, hindcasts are conducted; these simulations are setup similarly to the forecast except for a few points. The offshore wave conditions are obtained from NDBC buoy 46029 and applied uniformly to the offshore boundary. The side boundary conditions are determined by linearly shoaling the offshore spectra along the north and south bathymetric cross-shore sections. Tidal current information is obtained from a hindcast version of the SELFE model. The hindcasts are nested once; to produce a cross-shore and longshore resolution of $30 \mathrm{~m}$ and $50 \mathrm{~m}$ at the river mouth, respectively. Results from the hindcasts, though, show that there is insignificant difference in the model results from this increase in resolution. 

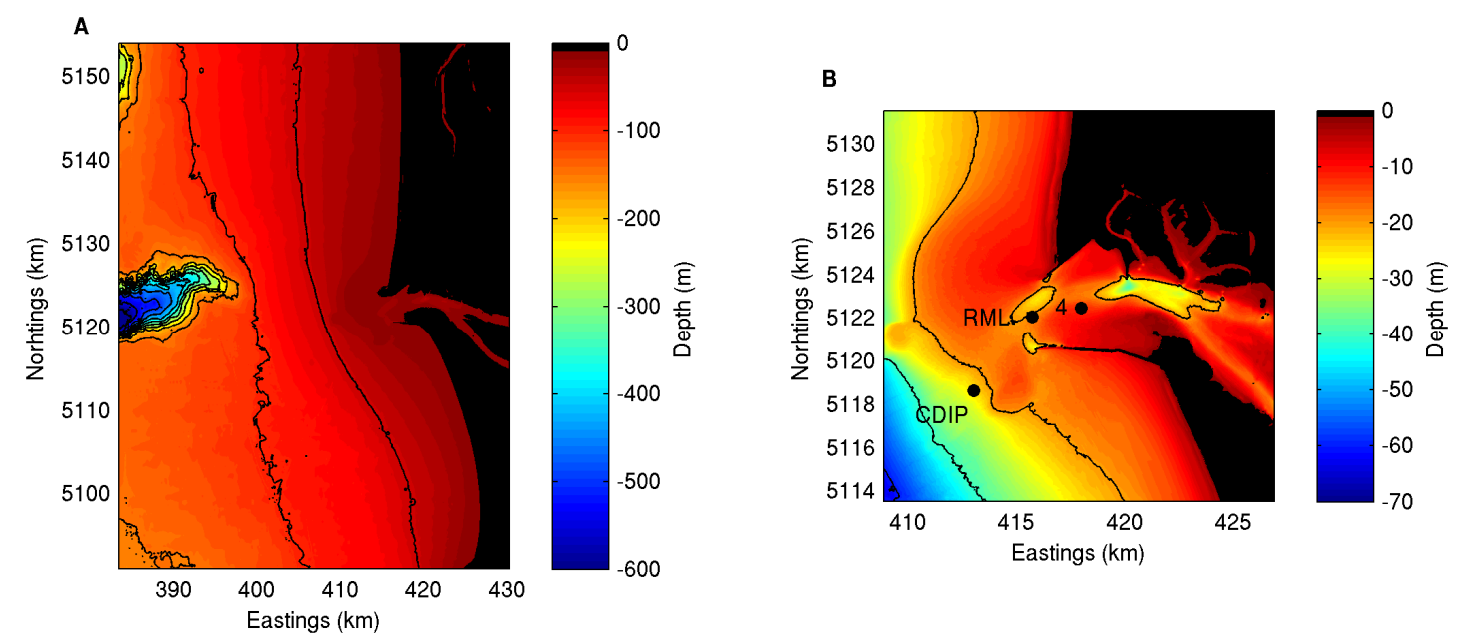

Figure 1. A. Model domain with contour lines in $50 \mathrm{~m}$ increments, starting at $600 \mathrm{~m}$ water depth. B. Bathymetry of river entrance. Contour lines are at $60 \mathrm{~m}, 40 \mathrm{~m}$ and $20 \mathrm{~m}$ water depth. Also shown is the location of the CDIP buoy, the river mouth location (RML) and station 4 during the MGT Experiment.

\section{RESULTS}

\section{Forecast}

Our Columbia River forecast has been providing wave predictions at the MCR since August 2011. Specifically, it gives bulk wave parameters throughout the domain and spectral information at the CDIP buoy and river mouth location. At the CDIP buoy, the forecast is able to predict waves with good accuracy (see Fig. 2). For the six-month period from August to December 2011, there is a $16 \%$ normalized root-mean-squared error (NRMSE) in wave height. Wave period is not as well predicted, with a NRMSE of 27\% (see Table 1). These statistics represent the performance of the first 24 hours of the forecast window. Over the 68-hours forecast period, the performance remains relatively constant; there is a minor increase in wave height NRMSE, and mean period and peak direction experience a decrease in error (see Fig. 3). The accuracy of offshore wave height, period and direction over the forecast period is reflected in the forecasted parameters at the buoy. From this, it is evident that as offshore errors increase (or decrease), so will model error at the buoy. The offshore wave height is overpredicted, with a bias of $4 \%$, however at the buoy, the model produces a bias of $-3 \%$ suggesting that the model consistently underpredicts wave heights at the buoy, despite an initial overprediction at the offshore boundary. There is significant improvement in the prediction of peak wave direction from offshore to the buoy. As waves propagate to shore, wave direction converges to become perpendicular to the bathymetry contours. Wave direction at the buoy is generally from the south, regardless of offshore direction. This is due to the river bar which creates large areas of refraction near the buoy. Thus initial errors in the offshore direction do not have a large effect on the model performance at the buoy since wave direction will eventually converge at the buoy to approach from the south.

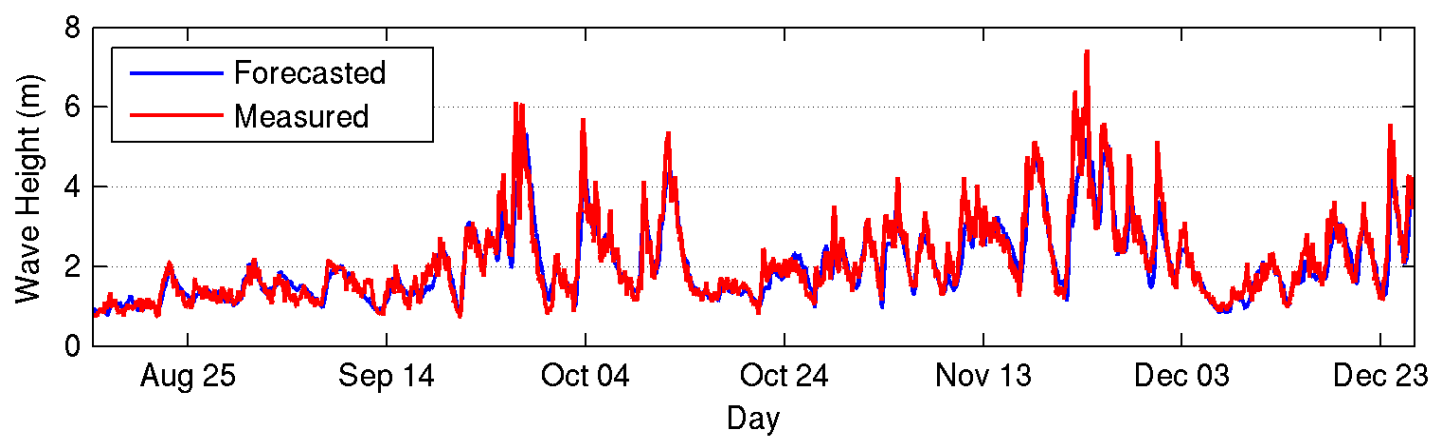

Figure 2. Forecasted and measured wave heights during a 6-month period at the CDIP buoy. 


\begin{tabular}{|c|ccc|ccc|}
\hline \multicolumn{2}{|c|}{ Table 1. Forecast results from August to December 2011 at the CDIP buoy } \\
\hline & \multicolumn{3}{c|}{ Offshore } & \multicolumn{3}{c|}{ CDIP buoy } \\
\cline { 2 - 7 } & $\mathrm{H}_{\mathrm{s}}$ & $\mathrm{T}_{\mathrm{m}}$ & $\mathrm{D}_{\mathrm{p}}$ & $\mathrm{H}_{\mathrm{s}}$ & $\mathrm{T}_{\mathrm{m}}$ & $\mathrm{D}_{\mathrm{p}}$ \\
\hline RMSE & $43 \mathrm{~cm}$ & $2.3 \mathrm{~s}$ & $35^{\circ}$ & $38 \mathrm{~cm}$ & $1.7 \mathrm{~s}$ & $23^{\circ}$ \\
NRMSE & $17 \%$ & $36 \%$ & - & $16 \%$ & $27 \%$ & - \\
BIAS & $9.6 \mathrm{~cm}$ & $1.9 \mathrm{~s}$ & $6^{\circ}$ & $-7 \mathrm{~cm}$ & $1.2 \mathrm{~s}$ & $-0.4^{\circ}$ \\
REL. BIAS & $4 \%$ & $26 \%$ & - & $-3 \%$ & $16 \%$ & - \\
\hline
\end{tabular}
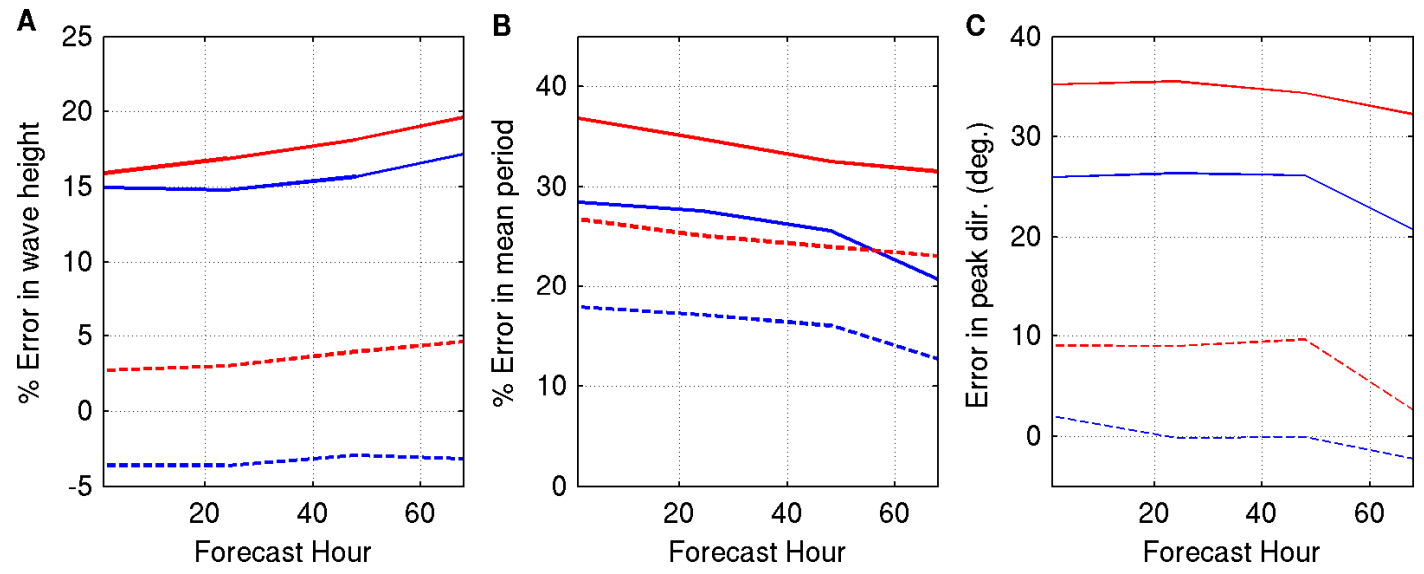

Figure 3. Model performance over the length of the forecast for offshore parameters obtained from NearWW3 (red) and parameters at the CDIP buoy from the MCR forecast (blue). In Figure A and B, the solid line is NRMSE and the dashed line is the relative bias. In Figure C, the solid line is the RMSE and the dashed line is the bias.

\section{August Hindcast}

Modeled wave heights at the river mouth location behave very differently compared to waves at the CDIP buoy, since they are dominated by the tidal currents. Validation at the river mouth is unavailable during the time period of the forecast, but in August 2005 a field experiment was conducted by the USACE and United States Geological Survey (USGS) at the MCR. The Mega-Transect Experiment (MGT) obtained measurements of waves and currents at 5 locations across the channel (Moritz et al. 2005). With this data set, validation of the input currents and wave-current interactions are possible. Currents obtained from a hindcast version of SELFE are compared against measured depth-average currents at station 4. Both the along-channel and cross-channel currents are well represented with NRMSE of $12 \%$ and $19 \%$, respectively, however the cross-channel currents are consistently underpredicted, especially on ebb tides. The modeled and measured wave heights at station 4 show a large tidal signature, where wave heights increase on ebb tides and decrease of flood tides (see Fig. 4). The model is able to correctly capture the general fluctuation in wave height but has a tendency to overpredict the extent of change due to ebb currents, resulting in a NRMSE of $30 \%$ and relative bias of $11 \%$. Some of the model errors are due to initial errors in the input velocities, but additional errors arise from only considering depth uniform currents. The vertical velocity profile at the MCR is heavily sheared; the top half of the water column generally experiences stronger currents than the bottom half, so high frequency waves will be affected by a stronger current and therefore the depth-averaged value is not the most representative for these cases.

\section{DISCUSSION}

Forecasting waves adds another level of complication since there is a degree of uncertainty in the offshore conditions. Hindcasts, which are forced with measured waves are expected to produce smaller errors and represent a baseline of model performance. The 6-month forecast period is repeated as a hindcast, where the input wave conditions are obtained from NDBC buoy 46029. For this hindcast, the forecasted tidal currents are still used because hindcasted current information was unavailable at the time. The results of the 6-month hindcast are shown in Table 2. As expected, the hindcast has a lower NRMSE for all wave parameters. The error in wave height is only reduced by $3 \%$, suggesting that the remaining error is due to model limitations such as non-linear and phase-resolved effects that the model is unable to capture. The bias in wave height increases, which is expected because there is no initial bias in the offshore wave heights, and as noted from the forecast, the model will underpredict wave heights 
at the buoy. There is a significant reduction in error in mean period and a minor improvement in peak direction estimates.

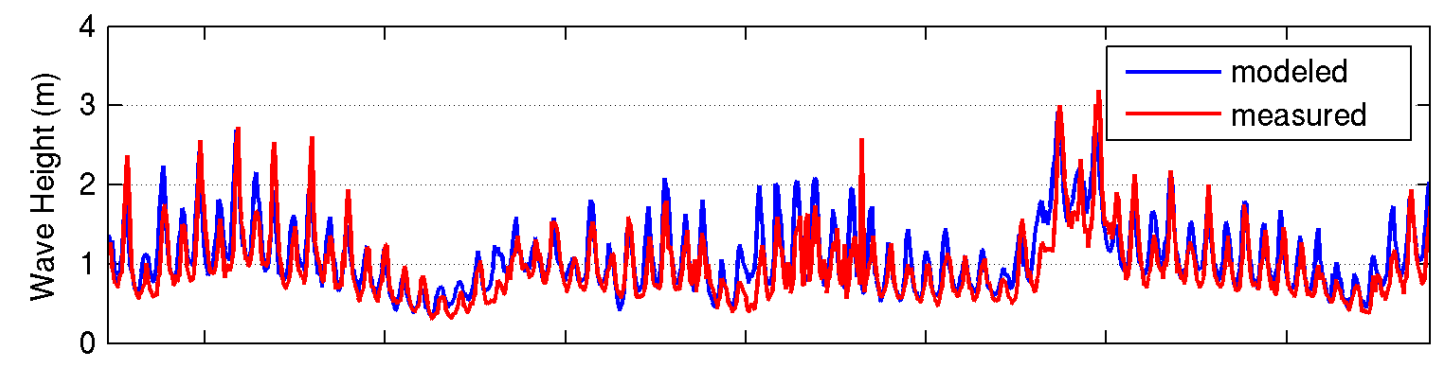

Figure 4. Modeled and measure wave heights at station 4 during the MGT Experiment.

\begin{tabular}{|c|c|c|c|}
\hline \multicolumn{4}{|c|}{ Table 2. Hindcast results from August to December 2011 at the CDIP buoy } \\
\hline & $\mathrm{H}_{\mathrm{s}}$ & $\mathrm{T}_{\mathrm{m}}$ & $\mathrm{D}_{\mathrm{p}}$ \\
\hline RMSE & $32 \mathrm{~cm}$ & $1.1 \mathrm{~s}$ & $19^{\circ}$ \\
NRMSE & $13 \%$ & $16 \%$ & - \\
BIAS & $-17 \mathrm{~cm}$ & $0.8 \mathrm{~s}$ & $-4^{\circ}$ \\
REL. BIAS & $-8 \%$ & $11 \%$ & - \\
\hline
\end{tabular}

\section{CONCLUSION}

A forecast is developed at the Columbia River estuary which predicts the wave conditions and wave-current interactions. The forecast is validated against buoy measurements for a 6-month period, resulting in a NRMSE of $16 \%$ in wave heights. The forecast period is repeated as a hindcast, in which the model is forced with measured conditions, resulting in a NRMSE of 13\%. This is done to establish the baseline of model performance and to separate forecast errors and model errors. Validation of the wave-current interaction is obtained through a 4-week hindcast in which the model is compared against in-situ measurements obtained from a field experiment in the river channel. This results in a NRMSE of $30 \%$ in wave heights at the river channel. Compared to the CDIP buoy, errors in the channel are greater, which may be due to several missing physical processes, including errors in velocity estimates and limitations in the wave-current interaction modeling. Despite some of these errors, the model is able to produce reliable results at the buoy and give qualitative estimate of wave conditions over the bar and in the channel.

\section{ACKNOWLEDGEMENTS}

The authors thank Rod Moritz of the US Army Corps of Engineers, Guy Gelfenbaum of the US Geological Survey, and Giles Lesser for the Mega-Transect Experiment dataset. We also thank Paul Turner and Antonio Baptista for access to the SELFE forecast.

\section{REFERENCES}

Allan, J.C., and P.D. Komar. 2002. Extreme storms on the Pacific Northwest coast during the 1997-98 el niño and 1998-99 la niña, Journal of Coastal Research, 18 (1), 175-193.

Battjes, J.A., and J.P.F.M Janssen. 1978. Energy loss and set-up due to breaking of random waves, Proceedings of the $16^{\text {th }}$ International Conference on Coastal Engineering, ASCE, 569-587.

Booij, N., Ris, R.C., and L.H. Holthuijsen. 1999. A third-generation wave model for coastal regions 1. Model description and validation. Journal of Geophysical Research, 104 (C4), 7649-7666.

Elias, E., Gelfenbaum, G., and A. Van der Westhuysen. 2012. Validation of a coupled wave-flow model in a high-energy setting: The mouth of the Columbia River, Journal of Geophysical Research, 117, $21 \mathrm{pp}$.

García-Medina, G., Özkan-Haller, H.T., Ruggiero, P., and J. Oskamp. 2012. A nearshore wave forecasting system for the US Pacific Northwest, Weather and Forecasting, (in review).

González, F.I. 1984. A case study of wave-current-bathymetry interactions at the Columbia River entrance, Journal of Physical Oceanography, 14 (6), 1065-1078.

Komen, G.J., Hasselmann, S., and K. Hasselmann. 1984. On the existence of a fully developed windsea spectrum, Journal of Physical Oceanography, 14, 1271-1285. 
Moritz, H.R., Gelfenbaum, G.R., and P. Ruggiero. 2005. Morphological implications of oceanographic measurements acquired along a mega-transect at the mouth of the Columbia River, USA. AGU Fall Meeting, Abstract OS23A-1534.

Moritz, H.R., Gelfenbaum, G.R., Kaminsky, G.M., Ruggiero, P., Oltman-Shay, J., and J.D. Mckillip. 2007. Implementing regional sediment management to sustain navigation at an energetic tidal inlet, Coastal Sediments 2007, ASCE.

Ruggiero, P., Kaminsky, G.M., Gelfenbaum, G., and B. Voigt. 2005. Seasonal to interannual morphodynamics along a high-energy dissipative littoral cell, Journal of Coastal Research, 21 (3), 553-578.

Zhang, Y., Baptista, A.M., and E.P. Myers III. 2004. A cross-scale model for 3D baroclinic circulation in estuary-plume-shelf systems: I. Formulation and skill assessment, Continental Shelf Research, 24 (18), 2187-2214. 